\title{
Pendampingan dan Pelatihan Ketrampilan Pemeriksaan Gula Darah, Asam Urat dan Kolesterol di Desa Toyareka Kecamatan Kemangkon
}

\author{
Feti Kumala Dewi ${ }^{1)}$, Wasis Eko Kurniawan ${ }^{2)}$ \\ Prodi Kebidanan D $3^{1)}$ Prodi Profesi Ners ${ }^{2)}$ \\ STIKES Harapan Bangsa Purwokerto \\ Jalan Raden patah no 100 Ledug Kembaran Banyumas \\ vettykumala@gmail.com \\ wasisekokurniawan@yahoo.co.id
}

\begin{abstract}
Peningkatan prevalensi penyakit tidak menular menjadi ancaman yang serius dalam pembangunan, karena mengancam pertumbuhan ekonomi nasional. Proporsi angka kematian akibat PTM, untuk Diabetes Melitus terjadi peningkatan pada tahun 2007 dari 1,1\% menjadi 2,1\% pada tahun 2013. Prevalensi hipertensi di Indonesia berdasarkan hasil pengukuran pada umur $\geq 18$ tahun sebesar 25,8\%. Prevalensi penyakit sendi berdasar diagnosis nakes di Indonesia 11,9\% dan berdasar diagnosis atau gejala 24,7\%. Faktor risiko terjadinya PTM adalah obesitas, tekanan darah tinggi, gula darah tinggi, dan kolesterol tinggi. Upaya pencegahan penyakit tidak menular lebih ditujukan kepada faktor risiko yang telah diidentifikasi. Target luaran yang akan dihasilkan dari kegiatan Pengabdian Masyarakat ini adalah meningkatanya informasi dan edukasi tentang penyakit Hipertensi, Diabetes Militus dan Asam Urat di Bina Keluarga Lansia dan Bina Keluarga Remaja, kader di Bina Keluarga Lansia dan Bina Keluarga Remaja dapat melakukan pengukuran IMT, tekanan darah, pemeriksaan gula darah, asam urat dan kolesterol. Serta tersedianya buku saku tentang deteksi dini penyakit Hipertensi, Diabetes Militus dan Asam Urat. Pengabdian masyarakat dilaksanakan Di Bina Keluarga Lansia sebanyak 30 kader dan Bina Keluarga Remaja sebanyak 30 kader. Pelaksanaan pada tanggal 25-28 Juni 2018. Setelah dilakukan pendampingan dan pelatihan pemeriksaan gula darah, asam urat dan kolesterol di Bina Keluarga Lansia ada perubahan signifikan, ini terbukti dengan perubahan ketrampilan baik meningkat sebelum pendampingan dan pelatihan ketrampilan baik sebanyak 2 ibu (10\%) menjadi ketrampilan baik sebanyak 11 ibu (55\%). Di Bina Keluarga Remaja ada perubahan signifikan sebelum pendampingan dan pelatihan ketrampilan baik sebanyak 3 ibu (15\%), menjadi ketrampilan baik sebanyak 13 ibu $(65 \%)$.
\end{abstract}

Keywords - Pendampingan dan pelatihan, ketrampilan pemeriksaan gula darah, asam urat dan kolesterol.

\section{Pendahuluan}

Peningkatan prevalensi penyakit tidak menular menjadi ancaman yang serius dalam pembangunan, karena mengancam pertumbuhan ekonomi nasional. Proporsi angka kematian akibat PTM, untuk Diabetes Melitus terjadi peningkatan pada tahun 2007 dari 1,1\% menjadi 2,1\% pada tahun 2013. Prevalensi hipertensi di Indonesia berdasarkan hasil pengukuran pada umur $\geq 18$ tahun sebesar $25,8 \%$. Prevalensi penyakit sendi berdasar diagnosis nakes di Indonesia $11,9 \%$ dan berdasar diagnosis atau gejala $24,7 \%$ (Riskesdas 2013).

Proporsi penyebab kematian PTM pada orang-orang berusia kurang dari 70 tahun, penyakit cardiovaskular merupakan penyebab terbesar (39\%), diikuti kanker (27\%), sedangkan penyakit pernafasan kronis, penyakit pencernaan dan PTM yang lain bersama-sama menyebabkan sekitar (30\%) kematian, serta 4\% kematian disebabkan diabetes (Riley \& Cowan, 2014). Berdasar Riset Kesehatan Dasar (Riskesdas) pada tahun 2013, 69,6\% dari kasus diabetes melitus dan $63,2 \%$ dari kasus hipertensi masih belum terdiagnosis. Keadaan ini mengakibatkan penanganan menjadi sulit, terjadi komplikasi bahkan berakibat kematian lebih dini. Kasus PTM untuk wilayah Provinsi Jawa Tengah Berdasar Riset Kesehatan dasar pada tahun 2012, PTM tertinggi adalah kelompok penyakit jantung dan pembuluh darah. Dari total 1.212.167 kasus dari 34 kabupaten yang dilaporkan sebesar 66,51\% (806.208 kasus), diikuti Diabetes Melitus sebesar 16,58\%, dan PPOK sebesar $1,61 \%$.

Prevalensi penduduk dengan tekanan darah tinggi secara nasional sebesar $30,9 \%$. Prevalensi tekanan darah tinggi 
pada perempuan $(32,9 \%)$ lebih tinggi dibanding dengan laki-laki $(28,7 \%)$. Prevalensi di perkotaan sedikit lebih tinggi $(31,7 \%)$ dibandingkan dengan pedesaan $(30,2 \%)$. Prevalensi semakin meningkat seiring dengan pertambahan umur. Prevalensi obesitas (Indeks Massa Tubuh atau IMT $=25-27$ dan IMT $=27$ ) sebesar 33,5\%, sedangkan penduduk obese dengan IMT =27 saja sebesar $20,6 \%$. Pada penduduk yang obesitas, prevalensi lebih tinggi pada perempuan $(41,4 \%)$ dibandingkan pada laki-laki $(24,0 \%)$. Prevelansi lebih tinggi di perkotaan $(38,3 \%)$ daripada perdesaan $(28,2 \%)$. Sedangkan menurut kelompok umur, obesitas tertinggi pada kelompok umur 40-49 tahun $(38,8 \%)$ (Profil Kesehatan Indonesia, 2016).

Berbagai faktor risiko PTM diantaranya adalah merokok dan keterpaparan terhadap asap rokok, diet/pola makan tidak sehat, kurang aktivitas fisik, konsumsi minuman beralkohol, dan riwayat keluarga (keturunan). Adapun faktor risiko terjadinya PTM adalah obesitas, tekanan darah tinggi, gula darah tinggi, dan kolesterol tinggi. Prinsip upaya pencegahan tetap lebih baik dari pengobatan. Upaya pencegahan penyakit tidak menular lebih ditujukan kepada faktor risiko yang telah diidentifikasi. Sehubungan dengan hal tersebut, Kementerian Kesehatan telah mengembangkan program pengendalian PTM sejak tahun 2006 (Profil Kesehatan Indonesia, 2016).

Salah satu bentuk Upaya Kesehatan Berbasis Masyarakat (UKBM) yang baru dikembangkan oleh Pemerintah sesuai dengan rekomendasi WHO agar memusatkan penanggulangan PTM melalui tiga komponen utama, yaitu surveilans faktor risiko, promosi kesehatan, dan pencegahan melalui inovasi dan reformasi manajemen pelayanan kesehatan adalah pos pembinaan terpadu penyakit tidak menular (Posbindu PTM) (Kemenkes, 2012). Diperlukan suatu upaya deteksi dini terkait dengan pencegahan berbagai PTM. Deteksi secara dini dapat dilakukan dengan pengecekan status gizi, tekanan darah, biokimia darah (khususnya glukosa darah, kolesterol) secara rutin. Tentunya hasil pada saat deteksi dini dapat digunakan sebagai dasar pencegahan atau penanganan masalah kesehatan masyarakat sehingga masyarakat dapat hidup secara berkualitas.

Berdasarkan data dari Puskesmas Kemangkon, di Desa Toyareka sudah terdapat Pos Pelayanan Terpadu (Posbindu), tetapi yang aktif hanya di RW 2 dari 4 RW. Dari Hasil pemeriksaan di Bina Keluarga Lansia, posbindu dan Bina Keluarga Remaja secara keseluruhan yaitu nilai tekanan darah yang yang tinggi (>140 mmhg) sebanyak 57 ibu $(36,31 \%)$. Nilai gula darah yang tinggi $(>180 \mathrm{mg} / \mathrm{dl})$ sebanyak 8 ibu $(5,1 \%)$. Nilai asam urat yang tinggi $(>5,7$ $\mathrm{mg} / \mathrm{dl})$ sebanyak 52 ibu $(33,12 \%)$. Nilai kolesterol yang tinggi (>200 mg/dl) sebanyak 14 ibu (8,92\%). Hasil pemeriksaan di Bina Keluarga Lansia, posbindu dan Bina Keluarga Remaja secara keseluruhan yaitu nilai tekanan darah yang yang tinggi (>140 mmhg) sebanyak $57 \mathrm{ibu}$ $(36,31 \%)$. Nilai gula darah yang tinggi $(>180 \mathrm{mg} / \mathrm{dl})$ sebanyak 8 ibu $(5,1 \%)$. Nilai asam urat yang tinggi $(>5,7$ $\mathrm{mg} / \mathrm{dl})$ sebanyak 52 ibu $(33,12 \%)$. Nilai kolesterol yang tinggi (>200 mg/dl) sebanyak $14 \mathrm{ibu} \mathrm{(8,92 \% ).} \mathrm{Apabila}$ masyarakat mempunyai keterampilan yang memadai tentang deteksi dini dan penanganan awal termasuk mencari pertolongan yang tepat maka kecacatan dan kematian akibat dari penyakit asam urat, kolesterol dan gula ini dapat diminimalkan. Sehubungan dengan hal tersebut perlu memberdayakan masyarakat dalam hal pelatihan dan pendampingan Pendampingan ketrampilan pemeriksaan gula darah, asam urat dan kolesterol.

\section{A. Solusi Yang Ditawarkan}

Solusi yang ditawarkan dalam penerapan Pengabdian Masyarakat ini adalah:

- Penyuluhan tentang penyakit Hipertensi, Diabetes Militus dan Asam Urat di Bina Keluarga Lansia dan Bina Keluarga Remaja.

- Pendampingan dan pelatihan tentang ketrampilan melakukan pengukuran IMT, tekanan darah, pemeriksaan gula darah, asam urat dan kolesterol.

- Menyediakan buku saku tentang deteksi dini penyakit Hipertensi, Diabetes Militus dan Asam Urat.

- Menyediakan kartu screening hasil pemeriksaan tekanan darah, BB dan TB (IMT), gula darah, asam urat serta kolesterol.

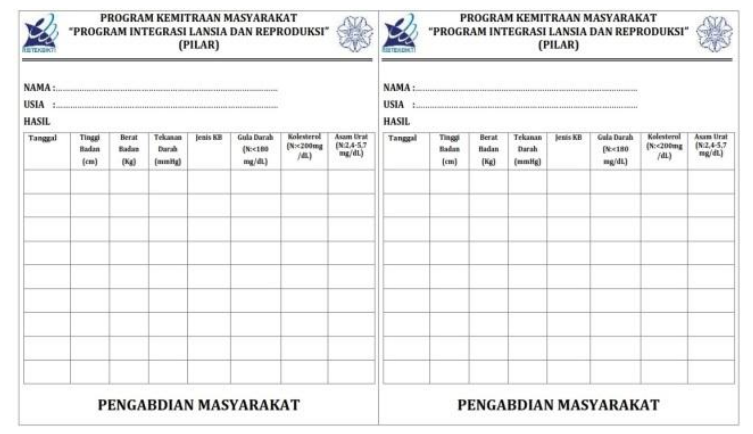

Gambar 1. Kartu screening kesehatan

\section{TARGET LUARAN}

Target luaran yang akan dihasilkan dari kegiatan Pengabdian Masyarakat ini adalah:

- Meningkatanya informasi dan edukasi tentang penyakit Hipertensi, Diabetes Militus dan Asam Urat di Bina Keluarga Lansia dan Bina Keluarga Remaja.

- Kader di Bina Keluarga Lansia dan Bina Keluarga Remaja dapat melakukan pengukuran IMT, tekanan darah, pemeriksaan gula darah, asam urat dan kolesterol.

- Buku saku tentang deteksi dini penyakit Hipertensi, Diabetes Militus dan Asam Urat. 


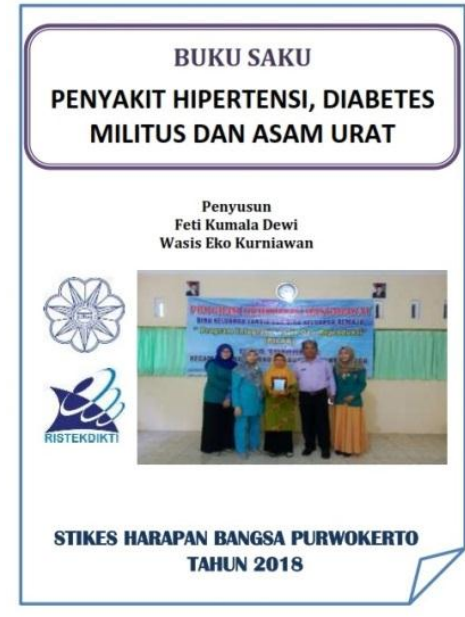

Gambar 2. Buku Saku

- Kartu screening hasil pemeriksaan tekanan darah, BB dan TB (IMT), gula darah, asam urat serta kolesterol.

\section{Metode PelaksanaAN}

Pengabdian masyarakat dilaksanakan Di Bina Keluarga Lansia sebanyak 30 kader dan Bina Keluarga Remaja sebanyak 30 kader. Pelaksanaan pada tanggal 25-28 Juni 2018.

\section{A. Materi}

Screening asam urat, gula darah, kolesterol meliputi pengertian, faktor penyebab peningkatan, kadar normal, cara menangani masalah.

\section{B. Metode/tahap-tahap pelaksanaan}

- Pendekatan kepada tokoh masyarakat mengenai kegiatan yang akan dilakukan

- Sosialisasi kegiatan dan mendata peserta dan menetapkan tempat kegiatan

- Menyiapkan materi pelatihan dan alat-alat pendukung.

- Sarana pendukung pada kegiatan ini antara lain alat-alat pemeriksaan

- Menyiapkan sumber daya manusia yang terlibat (pelaksana, ketua dan anggota Bina Keluarga Lansia dan Bina Keluarga Remaja, bidan, kader, mahasiswa)

- Nara sumber adalah dari team pelaksana Bidan Desa Toyareka dan Puskesmas Kemangkon

- Membuat undangan ke para peserta dan diberikan kepada peserta 3 hari sebelum kegiatan.

- Pelaksanaan kegiatan Pendampingan dan pelatihan ketrampilan pemeriksaan gula darah, asam urat dan kolesterol.

- Komunikasi, informasi dan edukasi tentang Kesehatan lansia : Screening asam urat, gula darah, kolesterol meliputi pengertian, faktor penyebab peningkatan, kadar normal, cara menangani masalah,
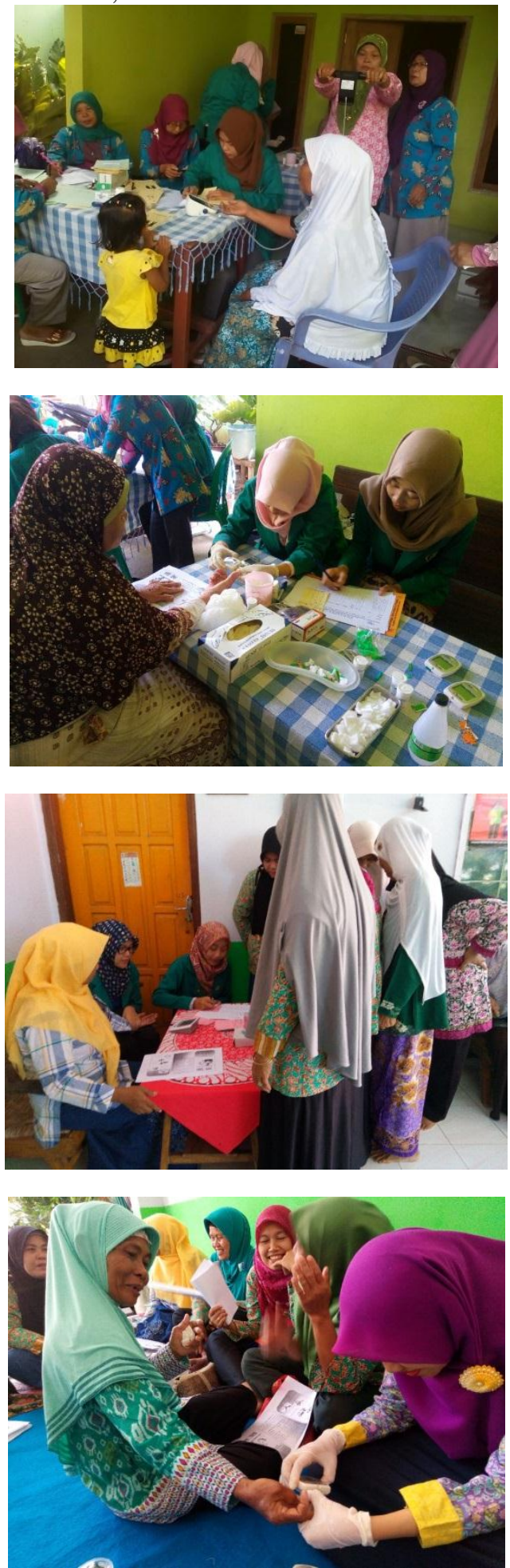

Gambar 3. Pelaksanaan kegiatan

C. Evaluasi Sebelum Dan Sesudah Kegiatan Pengabdian 
- Pendampingan dan pelatihan pemeriksaan Pemeriksaan Tinggi Badan, Berta Badan, Tekanan darah, gula darah, asam urat dan kolesterol sebagai kelompok pendukung kesehatan reproduksi dan kesehatan lansia.
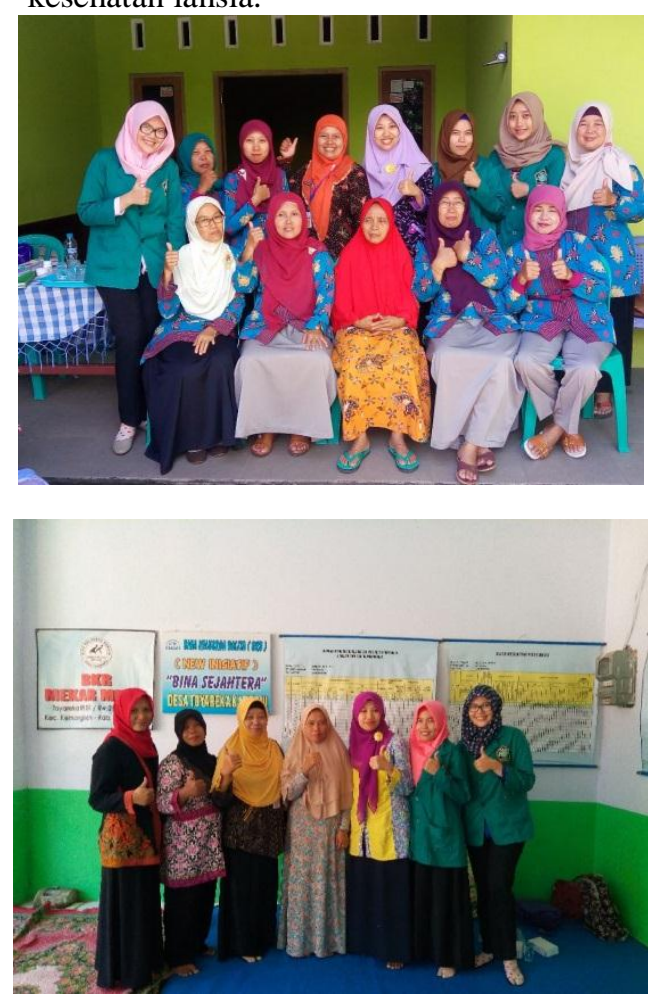

Gambar 4. Kader dan anggota yang dilatih pemeriksaan Badan, Berta Badan, Tekanan darah, gula darah, asam urat dan kolesterol.

- Melakukan evaluasi dan refleksi kembali serta penyempurnaan terhadap program yang telah dibuat dan ditindak lanjuti melalui program selanjutnya berkolaborasi dengan bidan desa.

- Monitoring dan evaluasi untuk bidan Puskesmas Kemangkon tentang hasil pemeriksaan asam urat, gula darah dan kolesterol sebagai deteksi penyakit gout, Diabetes Militus dan Penyakit jantung melalui kartu kontrol hasil pemeriksaan.

\section{IV.HASIL DAN PEMBAHASAN}

A. Pendampingan dan Pelatihan ketrampilan pemeriksaan gula darah, asam urat dan kolesterol di Bina Keluarga Lansia

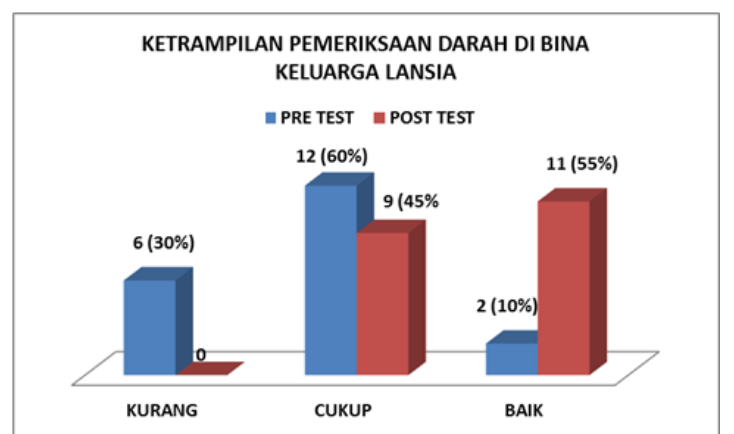

Gambar 5. Ketrampilan pemeriksaan gula darah, asam urat dan kolesterol di Bina Keluarga Lansia

Setelah dilakukan pendampingan dan pelatihan ketrampilan pemeriksaan gula darah, asam urat dan kolesterol di Bina Keluarga Lansia ada perubahan signifikan untuk ketrampilan responden. Ketrampilan sebelum pendampingan dan pelatihan ketrampilan baik sebanyak 2 ibu (10\%), setelah dilakukan pendampingan dan pelatihan tertinggi adalah ketrampilan baik sebanyak $11 \mathrm{ibu}$ $(55 \%)$.

B. Pendampingan dan Pelatihan ketrampilan pemeriksaan gula darah, asam urat dan kolesterol Di Bina Keluarga Remaja

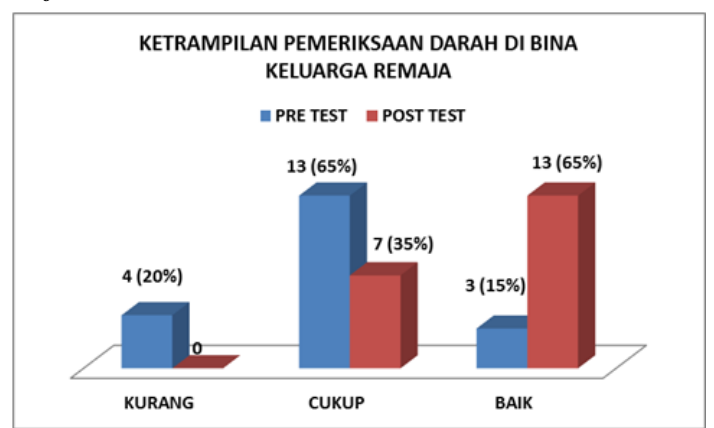

Gambar 6. Ketrampilan pemeriksaan gula darah, asam urat dan kolesterol di Bina Keluarga Remaja

Setelah dilakukan pendampingan dan pelatihan ketrampilan pemeriksaan gula darah, asam urat dan kolesterol di Bina Keluarga Remaja ada perubahan signifikan untuk ketrampilan responden. Ketrampilan sebelum pendampingan dan pelatihan ketrampilan baik sebanyak 3 ibu (15\%), setelah dilakukan pendampingan dan pelatihan tertinggi adalah ketrampilan baik sebanyak $13 \mathrm{ibu}$ $(65 \%)$.

Ketrampilan kader di Bina Keluarga Lansia dan Bina Keluarga Remaja di dukung oleh beberapa faktor ketrampilan teknis antara lain umur, pendidikan atau pengetahuan, pekerjaan, lama menjadi kader serta kemampuan kader yang menunjukkan unsur kematangan dan ketrampilan yang dapat di peroleh dari pendidikan, latihan dan pengetahuan tersebut. 
Ketrampilan yang kurang sebanyak 6 ibu (30\%), 4 ibu (20\%) dan ketrampilan cukup sebayak $12(60 \%)$ dan $13 \mathrm{ibu}$ (65\%) yang di miliki kader menunjukan bahwa kemampuan yang di miliki oleh kader di Bina Keluarga Lansia dan Bina Keluarga Remaja belum maksimal dalam melakukan pemeriksaan gula darah, asam urat dan kolesterol. Hal ini disebabkan karena pada awal sebelum pelatihan dan pendampingam semua kader belum pernah mencoba melakukan pemeriksaan dan merasa takut melihat darah.

Setelah dilakukan pendampingan dan pelatihan pemeriksaan gula darah, asam urat dan kolesterol di Bina Keluarga Lansia ada perubahan signifikan, ini terbukti dengan perubahan ketrampilan baik meningkat sebelum pendampingan dan pelatihan ketrampilan baik sebanyak 2 ibu (10\%) menjadi ketrampilan baik sebanyak $11 \mathrm{ibu}$ (55\%). Di Bina Keluarga Remaja ada perubahan signifikan sebelum pendampingan dan pelatihan ketrampilan baik sebanyak 3 ibu (15\%), menjadi ketrampilan baik sebanyak $13 \mathrm{ibu}(65 \%)$. Respon peserta pendampingan dan pelatihan sangat antusias serta bersemangat, sehingga kegiatan berjalan lancar.

\section{SIMPULAN DAN SARAN}

\section{A. Simpulan}

Kader di Bina Keluarga Lansia dan Bina Keluarga Remaja mendukung kegiatan pencegahan penyakit tidak menular khususnya penyakit hipertensi asam urat dan Diabetes Militus, dilaksanakan dalam bentuk dapat melakukan pemeriksaan gula darah, asam urat dan kolesterol.

\section{B. Saran}

Kepada Bina Keluarga Lansia, Posbindu dan Bina Keluarga Remaja agar rutin melaksanakan screening Diabetes Militus, koleterol dan Penyakit asam urat setiap 6 bulan dengan memanfaatkan anggota/ kader yang sudah dilatih untuk pemeriksaan Tinggi Badan, Berta Badan, Tekanan darah, gula darah, asam urat dan kolesterol terutama kepada peserta yang tekanan darah tinggi, kadar gula darah, asam urat dan kolesterol terdeteksi tinggi melebihi normal.

\section{UCAPAN TERIMA KASIH}

Penulis mengucapkan terimakasih kepada DRPM Ditjen Penguatan Risbang RISKTEKDIKTI dan STIKES Harapan Bangsa Purwokerto yang mendanai penelitian ini, kader kesehatan di Bina Keluarga Lansia dan Bina Keluarga Remaja, serta Bidan Desa Toyareka yang banyak membantu terselenggara penelitian ini.

\section{DAFTAR PUSTAKA}

[1] Atun A. 2010. Lansia Sehat dan Bugar. Jakarta: Kreasi Wacana [2] Baziad A.2010.Menopause dan Permasalahanya. Jakarta: YBPSP

[3] Dinas Kesehatan Provinsi Jawa Tengah, (2015) Buku Profil Kesehatan Provinsi Jawa Tengah Tahun 2015. http://dinkesjatengprov.go.id/v2015/dokumen/profil2015/Profil_201 5_fix.pdf

[4] Kemenkes RI, 2010, Penuntun Hidup Sehat, Jakarta

[5] Kemenkes RI. 2012. Petunjuk Teknik Pos Pembinaan Terpadu Penyakit Tidak Menular (Posbindu TPM). Jakarta

[6] Kemenkes RI. 2013. Riset Kesehatan Dasar 2013 http://www.depkes.go.id/resources/download/general/Hasil\%20Risk esdas\%202013.pdf

[7] Kemenkes RI.2014. Buku Kesehatan Ibu dan Anak. Jakarta

[8] Kemenkes RI. 2017. Profil Kesehatan Indonesia 2016. Jakarta

[9] Prawirohardjo, Sarwono. 2008. Ilmu Kandungan Jakarta: Yayasan Bina Pustaka. 